Психология. Журнал Высшей школы экономики,

2021. T. 18. № 3. C. 475-490. DOI: 10.17323/1813-8918-2021-3-475-490

\title{
АДАПТАЦИЯ РУССКОЯЗЫЧНОЙ ВЕРСИИ ОПРОСНИКА МОТИВАЦИИ ИГРЫ В МАССОВЫЕ МНОГОПОЛЬЗОВАТЕЛЬСКИЕ РОЛЕВЫЕ ОНЛАЙН-ИГРЫ (ММОРПГ) НИКА ЙИ
}

\author{
Н.В. БОГАЧЕВА ${ }^{\text {a }}$ В.Е. ЕПИШИН ${ }^{\mathrm{a}}$, А.В. МИЛЬЯНСКАЯ
}

${ }^{a}$ Первый Московский государственный медицинский университет имени И.М. Сеченова, 119991, Россия, Москва, ул. Большая Пироговская, д. 2, стр. 4

\begin{abstract}
Резюме
Цель исследования - адаптация русскоязычной версии опросника мотивации игры в ММОРПГ Ника Йи. В исследовании участвовали 538 человек (72.5\% мужчин) в возрасте 12-40 лет. Для оценки внешней валидности опросника использовались «Шкала мотивации гейминга» (GAMS) и опросник опыта потока в групповых ролевых играх. Итоговая версия опросника воспроизводит оригинальную факторную структуру, но содержит 24 пункта из 39. Показатели пригодности итоговой модели $(\mathrm{CFI}=0.95 ; \mathrm{RMSEA}=0.042)$ демонстрируют хорошую согласованность модели и эмпирических данных. Показатели внутренней согласованности шкал опросника ( $\alpha$ Кронбаха) варьируют в диапазоне 0.619 0.906. Корреляции шкал опросника со шкалами GAMS и опросника опыта потока подтверждают его конструктную валидность. С внутренней мотивацией, интегративной и интроецированной регуляцией (GAMS) преимущественно связаны факторы шкалы мотивации погружения. Идентифицированная и внешняя регуляции коррелируют в основном со шкалами социальной мотивации и мотивации достижения. Все шкалы мотивации игры в ММОРПГ связаны с переживанием опыта потока, также множественные корреляции демонстрируют шкалы достижения и социальной мотивации опросника Йи с ориентацией на общение и шкалой продуманность-спонтанность опросника опыта потока. Обнаружены значимые межполовые различия в мотивации игры: у мужчин более выражен фактор механики (мотивация достижения), а у женщин - факторы эскапизма и кастомизации (мотивация погружения). Адаптированный опросник Ника Йи может считаться достаточно надежным и валидным инструментом для изучения мотивации игроков в онлайн-компьютерные игры.
\end{abstract}

Ключевые слова: компьютерные игры, мотивация игры, геймеры, онлайн-игры, компьютерные игроки, адаптация опросника.

\section{Введение}

Опосредствованная компьютерами и Интернетом игровая деятельность является предметом психологических исследований на протяжении нескольких десятилетий. Одно из наиболее значимых изменений, произошедших за это время с видеоиграми, - появление многопользовательских онлайн-игр, 
поддерживающих одновременную совместную игру сотен игроков. Аудитория видеоигр постоянно растет, превышая в России 65 миллионов человек (Седых, 2020). В связи с этим часто высказывается обеспокоенность возможными негативными последствиями увлечения компьютерными играми (зависимость, рост агрессивности и импульсивности у так называемых геймеров и др.). Мотивационно-смысловая сфера игроков при этом остается сравнительно малоизученной, но большинство ученых согласны, что компьютерная игровая деятельность полимотивирована (Olson, 2010; Иванова, 2020). При этом уже в ранних психологических исследованиях мотивация компьютерной игры рассматривалась в качестве одного из факторов, определяющих ее психологическое воздействие (Фомичева и др., 1991).

Наиболее известная ранняя классификация геймеров по критерию мотивации, предложенная Ричардом Бартлом, была рассчитана на игроков в многопользовательские игры жанра MUD (Multi User Dungeon, предшественник современных онлайн-игр) (Bartle, 1996). Он выделил четыре основных мотива игры: ориентацию на игроков или на игровой мир, на взаимодействие или на воздействие. По сочетанию этих мотивов выделяются четыре типа игроков: «достигающие», ориентированные на получение наград и очков; «исследователи», стремящиеся полностью изучить игровой мир; «социализирующиеся», заинтересованные главным образом в коммуникации, и «убийцы», стремящиеся мешать другим игрокам. При том, что работа Бартла носила теоретический характер и неоднократно критиковалась впоследствии, она послужила основой для ряда современных исследований мотивации геймеров (Yeе, 2006).

Вдохновлялось работой Бартла и исследование мотивации игроков в массовые многопользовательские ролевые онлайн-игры (ММОРПГ) Ника Йи. Как и одиночные ролевые компьютерные игры, ММОРПГ связаны с принятием игроком роли определенного персонажа, имеющего уникальную внешность, характеристики, историю. Принципиальная особенность ММОРПГжанра - одновременное присутствие в игре множества игроков, которые могут общаться, кооперироваться для совместной игры или противостоять друг другу (Sellers, 2006). Изначально опросник Йи отталкивался от предположений Бартла, но факторный анализ показал наличие десяти компонентов игровой мотивации, образующих три независимых фактора: достижение, погружение и социализацию. Мотивация достижения объединяет все, что касается прогресса в игре, соревновательный элемент и стремление разобраться в технических аспектах. Мотивация погружения связана с ролевыми элементами и глубоким интересом к игровому миру. Социальная мотивация отражает интерес к различным аспектам взаимоотношений между игроками (Yeе, 2006). Подробнее шкалы описаны в разделе «Методики».

Модель игровой мотивации Йи более гибкая, чем типология Бартла, и позволяет составлять индивидуальные мотивационные профили геймеров, а также устанавливать связи с другими психологическими и демографическими характеристиками. Так, например, установлена связь мотивации эскапизма (фактор мотивации погружения) и мотивации развития персонажа (фактор 
мотивации достижения) с игровой зависимостью, установлена межполовая и возрастная специфика мотивации онлайн-геймеров (Yеe, 2006).

Наряду с моделью игровой мотивации Ника Йи, исследования мотивации игроков в компьютерные игры часто опираются на теорию опыта потока Михая Чиксентмихайи. Возникновение в процессе игры «опыта потока» особого состояния удовлетворенности, возникающего при погружении в какую-либо деятельность, сопряженного с потерей чувства времени и своего Я, ощущением контроля за своими действиями и восприятием процесса деятельности как награды, неоднократно исследовалось психологами (Войскунский и др., 2005; Olson, 2010), в том числе в контексте возникновения зависимости от видеоигр (Ван и др., 2011), однако выводы относительно видеоигр до сих пор являются предметом дискуссий (Andrade, Pontes, 2017).

Все чаще для описания игровой мотивации применяется теория самодетерминации Эдварда Деси и Ричарда Райана, легшая в основу моделей игровой мотивации PENS (Ryan et al., 2006) и GAMS (Lafrenière et al., 2012; Иванова и др., 2016). PENS (Player Experience of Need Satisfaction, - Опыт игрока в удовлетворении потребностей) фокусируется на переживании во внутриигровом опыте игрока чувства компетентности, автономии, эффекта присутствия и интуитивности игрового управления. Данная модель базируется на мини-теории когнитивной оценки, описывающей влияние внешних факторов на внутреннюю мотивацию субъекта (Ryan et al., 2006). Опросник GAMS в большей степени фокусируется на различных формах внешней мотивации игроков в компьютерные игры (Lafrenière et al., 2012). Обе эти методики соотносились с различными версиями моделей игровой мотивации Йи (Ryan et al., 2006; Иванова, 2020), что, с одной стороны, указывает на значимость его работ в данной области, а с другой - позволяет использовать эти модели для валидизации русской версии опросника Йи.

Целью нашего исследования является адаптация на русскоязычной выборке методики «Мотивация игры в многопользовательские ролевые онлайнигры» (Үее, 2006). Несмотря на вклад работ Йи в современные представления о мотивации геймеров, полноценная русскоязычная адаптация данной методики прежде не проводилась. Наличие надежной русской версии опросника расширит возможности дальнейшего изучения мотивации игры, а также упростит сопоставление результатов отечественных и зарубежных исследований в этой области.

\section{Материалы и методы}

\section{Выборка}

В исследовании приняли участие 538 респондентов (148 женщин, 390 мужчин) в возрасте от 12 до 40 лет $(\mathrm{M}=21.25, \mathrm{Me}=20, \mathrm{SD}=5.17)$. Опрос проводился онлайн посредством Google Forms. Перед заполнением методик участникам предъявлялась форма информированного согласия. 


\section{Прочедура}

Опросник «Мотивация игры в ММОРПГ» (Yее, 2006) был переведен на русский язык независимо двумя русскоязычными переводчиками. Обратный перевод на английский выполнили два носителя английского языка. Переводы совмещала и сличала с оригинальным опросником экспертная комиссия, после чего был начат сбор данных.

Статистическая обработка осуществлялась с использованием IBM ® SPSS ® Statistics (Version 22) и IBM ® SPSS ® Amos 22.0.0.

\section{Методики}

1. Опросник «Мотивация игры в ММОРПГ» Ника Йи (Yeе, 2006), состоящий из 39 вопросов, оцениваемых по пятибалльной шкале (формулировки ответов варьируются в зависимости от вопроса, см. приложение). Опросник включает следующие шкалы:

а) прогресс - мотивация достижения игровых целей, быстрого развития персонажа, накопления ресурсов;

б) механика - шкала описывает стремление к пониманию математических основ игры для лучшего развития персонажа;

в) соревнование - мотивация подразумевает получение удовольствия от состязания с другими игроками нормативными (внутриигровыми) и ненормативными (с использованием провокации, обмана, грубости) методами;

г) общение - игра ради общения с другими игроками в форме непосредственно разговоров или в результате совместной игры;

д) отношения - игровая мотивация, связанная с установлением значимых межличностных отношений с другими игроками;

е) командная работа - игра ради совместной деятельности, коллаборации с другими игроками;

ж) исследование - мотивация изучения игрового мира, поиск редких игровых зон, заданий, предметов;

3) отыгрывание роли - мотивация, связанная с погружением и продумыванием истории персонажа игрока и игрового мира;

и) кастомизация (от англ. customization - настройка) - интерес к модификации внешнего вида игрового персонажа, созданию для него уникального стиля;

к) эскапизм - использование мира игры для отвлечения от проблем и стресса в реальной жизни.

Прогресс, механика и соревнования образуют глобальную шкалу Достижение; общение, отношения и социализация - шкалу Социальная мотивация; оставшиеся шкалы входят в глобальную шкалу Погружение.

2. Опросник «Шкала мотивации гейминга» (Gaming Motivation Scale, GAMS) (Lafrenière et al., 2012) в русскоязычной модификации Н.А. Ивановой (Иванова и др., 2016) содержит 18 утверждений, оцениваемых по 5-балльной шкале от «не согласен» до «согласен» и измеряет 6 типов мотивации: внутрен- 
нюю мотивацию, амотивацию, внешнюю регуляцию, идентифицированную регуляцию, интегративную (встроенную) регуляцию и интроецированную регуляцию. Последние четыре шкалы отражают разные виды внешней мотивации.

3. Опросник опыта потока в групповых ролевых играх А. Е. Войскунского (Войскунский и др., 2005). Методика стоит из 32 пунктов, образующих 6 факторов: переживание «опыта потока»; ориентация на достижение успеха; активность-пассивность; ориентация на общение; продуманность-спонтанность; познавательная потребность.

4. Анкета с социально-демографическими данными, вопросами об уровне игровой активности и любимых видеоиграх.

\section{Результаты}

\section{Проверка факторной структуры опросника}

На первом этапе с помощью конфирматорного факторного анализа тестировались три измерительные модели: 1) Модель 1 не включала ковариаций между факторами; 2) Модель 2 включала ковариации между всеми факторами; 3) Модель 3 включала три группы ковариционно-связанных факторов, отражающих факторную структуру оригинального опросника. Результаты тестирования моделей приведены в таблице 1

Рассчитанные показатели пригодности моделей не достигают рекомендуемых значений (Hu, Bentler, 1999). С целью их улучшения были исключены вопросы, имеющие факторную нагрузку ниже 0.5. Исключение было сделано для шкалы отыгрывания роли, поскольку два из трех утверждений в ней имели нагрузку ниже 0.5. После исключения низко нагруженных вопросов из первоначальных 39 остались 24 вопроса.

Показатели пригодности для моделей 2 и 3 с исключенными утверждениями приведены в таблице 2 .

Обе протестированные модели демонстрируют достаточные индексы пригодности. Для дальнейшей работы была выбрана Модель 3, так как ее показатели несколько лучше, чем у Модели 2 (см. рисунок 1).

Таблица 1

Показатели пригодности измерительных моделей

\begin{tabular}{|c|c|c|c|c|c|c|c|c|}
\hline & $\boldsymbol{\chi}^{2}$ & df & $\boldsymbol{p}$ & CFI & TLI & RMSEA & PCLOSE & AIC \\
\hline Модель 1 & 3683.177 & 702 & 0.000 & 0.618 & 0.597 & 0.089 & 0.000 & 3839.177 \\
\hline Модель 2 & 2536.185 & 657 & 0.000 & 0.759 & 0.729 & 0.073 & 0.000 & 2782.185 \\
\hline Модель 3 & 2751.608 & 690 & 0.000 & 0.736 & 0.717 & 0.075 & 0.000 & 2931.608 \\
\hline
\end{tabular}


Таблица 2

Показатели пригодности моделей после удаления низко нагруженных пунктов

\begin{tabular}{|c|c|c|c|c|c|c|c|c|}
\hline & $\boldsymbol{\chi}^{2}$ & df & $\boldsymbol{p}$ & CFI & TLI & RMSEA & PCLOSE & AIC \\
\hline Модель 2 & 436.779 & 206 & 0.000 & 0.95 & 0.932 & 0.046 & 0.882 & 624.779 \\
\hline Модель 3 & 468.555 & 238 & 0.000 & 0.95 & 0.942 & 0.042 & 0.986 & 592.555 \\
\hline
\end{tabular}

Рисунок 1

\section{Структура русской версии опросника «Мотивация игры в ММОРПГ» Ника Йи}

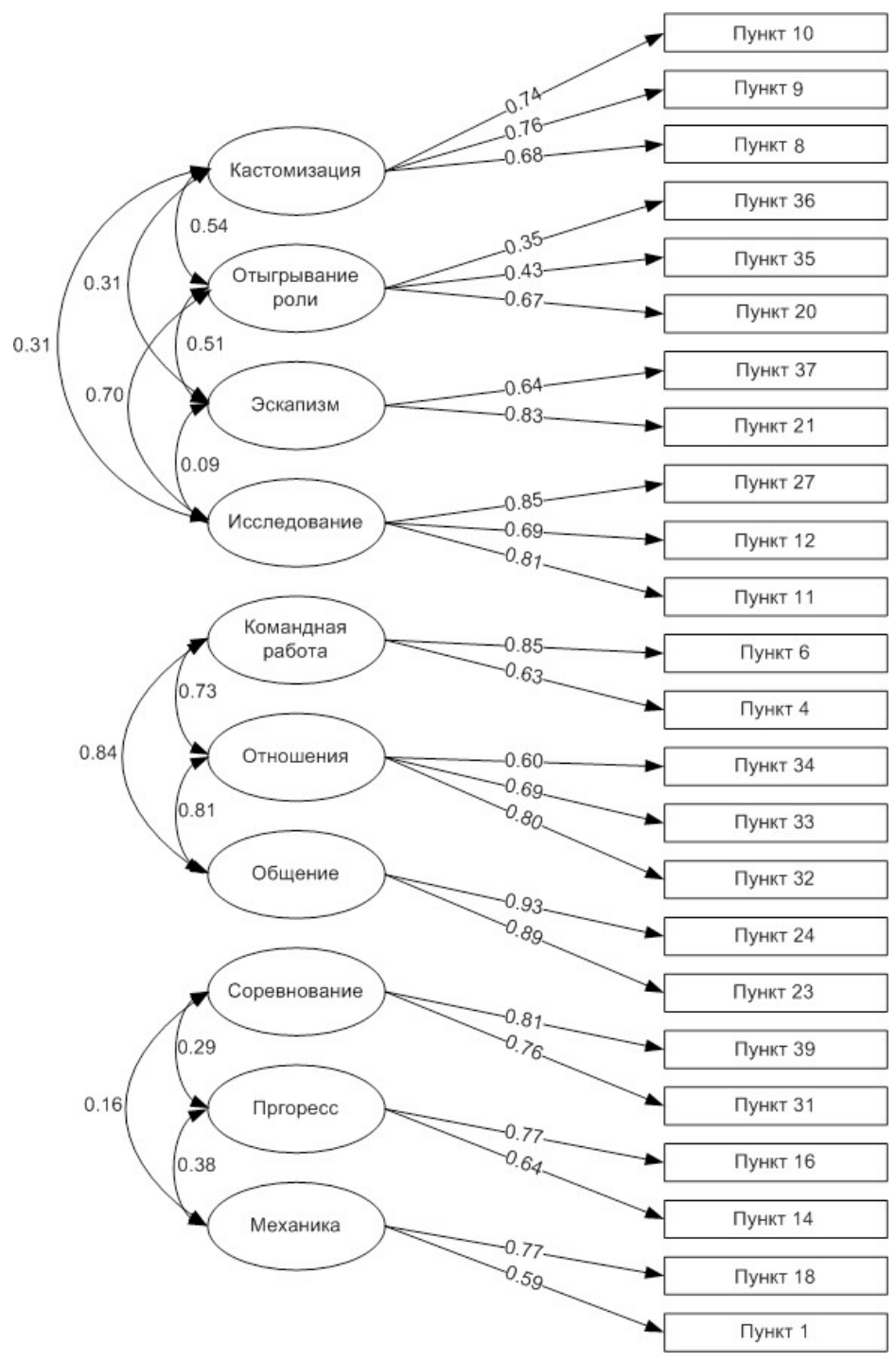




\section{Оценка надежности}

Оценка внутренней согласованности шкал опросника осуществлялась с помощью коэффициента $\alpha$ Кронбаха. Результаты приведены в таблице 3.

Для всех шкал опросника показатели внутренней согласованности являются приемлемыми.

\section{Оченка внешней валидности}

Оценка внешней валидности опросника осуществлялась с расчетом корреляции Пирсона между его шкалами и шкалами опросников GAMS и опыта потока. Значимость корректировалась с помощью поправки ХолмаБонферрони. Результаты приведены в таблицах 4 и 5.

Внутренняя мотивация наиболее тесно связана со шкалой Погружение и ее компонентами, за исключением исследования, а также с фактором прогресса шкалы Достижение. Внешняя регуляция связана в шкале Достижение с механикой и прогрессом; с фактором отношений шкалы Социальной мотивации; с отыгрыванием роли и кастомизацией, относящимися к мотивации Погружения. Идентифицированная регуляция значимо коррелирует со всеми шкалами Социальной мотивации и прогрессом. Шкала встроенной регуляции коррелирует со всеми факторами Погружения, а также с фактором механики. Интроецированная регуляция показала корреляции с эскапизмом, отыгрыванием роли и кастомизацией. Амотивация значимо не связана со шкалами опросника Н. Йи.

Разные аспекты переживания опыта потока связаны с различными игровыми мотивациями. Познавательная потребность значимо коррелирует с исследованием, эскапизмом и отыгрыванием роли шкалы Погружение, а

Таблица 3

Внутренняя согласованность шкал русскоязычной версии опросника Ника Йи

\begin{tabular}{|l|c|}
\hline \multicolumn{1}{|c|}{ Фактор } & Альфа Кронбаха \\
\hline Механика & 0.619 \\
\hline Прогресс & 0.657 \\
\hline Соревнование & 0.837 \\
\hline Общение & 0.906 \\
\hline Отношения & 0.780 \\
\hline Командная работа & 0.690 \\
\hline Исследование & 0.822 \\
\hline Эскапизм & 0.691 \\
\hline Отыгрывание роли & 0.632 \\
\hline Кастомизация & 0.766 \\
\hline
\end{tabular}


Корреляции шкал опросников Ника Йи и GAMS (n = 432)

Таблица 4

\begin{tabular}{|l|c|c|c|c|c|}
\hline \multicolumn{1}{|c|}{ ІІкалы } & $\begin{array}{c}\text { Внутренняя } \\
\text { мотивация }\end{array}$ & $\begin{array}{c}\text { Внешняя } \\
\text { регуляция }\end{array}$ & $\begin{array}{c}\text { Идентифици- } \\
\text { рованная } \\
\text { регуляция }\end{array}$ & $\begin{array}{c}\text { Интегративная } \\
\text { (встроенная) } \\
\text { регуляция }\end{array}$ & $\begin{array}{c}\text { Интроециро- } \\
\text { ванная } \\
\text { регуляция }\end{array}$ \\
\hline Механика & 0.180 & $0.266^{* *}$ & 0.167 & $0.221^{* *}$ & 0.149 \\
\hline Прогресс & $0.270^{* *}$ & $0.355^{* *}$ & $0.224^{* *}$ & 0.089 & 0.152 \\
\hline Соревнование & 0.072 & 0.150 & 0.021 & -0.043 & 0.135 \\
\hline Общение & 0.045 & 0.160 & $0.419^{* *}$ & 0.031 & 0.037 \\
\hline Отношения & 0.120 & $0.254^{* *}$ & $0.487^{* *}$ & 0.183 & 0.143 \\
\hline $\begin{array}{l}\text { Командная } \\
\text { работа }\end{array}$ & 0.039 & 0.122 & $0.379^{* *}$ & -0.026 & 0.041 \\
\hline Исследование & 0.171 & 0.138 & 0.075 & $0.216^{* *}$ & 0.132 \\
\hline Эскапизм & $0.276^{* *}$ & 0.124 & 0.101 & $0.302^{* *}$ & $0.430^{* *}$ \\
\hline $\begin{array}{l}\text { Отыгрывание } \\
\text { роли }\end{array}$ & $0.228^{* *}$ & $0.208^{* *}$ & 0.156 & $0.266^{* *}$ & $0.194^{* *}$ \\
\hline Кастомизация & $0.211^{* *}$ & $0.213^{* *}$ & 0.104 & $0.195^{* *}$ & $0.262^{* *}$ \\
\hline Достижение & $0.255^{* *}$ & $0.378^{* *}$ & $0.201^{* *}$ & 0.125 & $0.213^{* *}$ \\
\hline $\begin{array}{l}\text { Социальная } \\
\text { мотивация }\end{array}$ & 0.086 & $0.217^{* *}$ & $0.504^{* *}$ & 0.089 & 0.094 \\
\hline Погружение & $0.322^{* *}$ & $0.257^{* *}$ & 0.161 & $0.354^{* *}$ & $0.363^{* *}$ \\
\hline
\end{tabular}

Корреляции шкал опросников Ника Йи и опыта потока $(\mathrm{n}=538)$

\begin{tabular}{|l|c|c|c|c|c|c|}
\hline \multicolumn{1}{|c|}{ Шкалы } & $\begin{array}{c}\text { Переживание } \\
\text { попыта } \\
\text { потока» }\end{array}$ & $\begin{array}{c}\text { Ориентация } \\
\text { на достиже- } \\
\text { ние успеха }\end{array}$ & $\begin{array}{c}\text { Активность- } \\
\text { пассивность }\end{array}$ & $\begin{array}{c}\text { Ориентация } \\
\text { на обение }\end{array}$ & $\begin{array}{c}\text { Проду- } \\
\text { манность }-\end{array}$ & $\begin{array}{c}\text { Познава- } \\
\text { тельная }\end{array}$ \\
\hline Механиканность & 0.152 & $0.322^{* *}$ & $0.258^{* *}$ & 0.153 & $0.317^{* *}$ & $0.223^{* *}$ \\
\hline Прогресс & $0.229^{* *}$ & $0.461^{* *}$ & 0.148 & $0.259^{* *}$ & $0.301^{* *}$ & 0.068 \\
\hline Соревнование & 0.117 & 0.111 & 0.094 & $0.183^{* *}$ & 0.116 & -0.088 \\
\hline Общение & $0.191^{* *}$ & 0.088 & 0.100 & $0.762^{* *}$ & $0.296^{* *}$ & 0.026 \\
\hline Отношения & $0.250^{* *}$ & 0.118 & 0.169 & $0.644^{* *}$ & $0.280^{* *}$ & 0.062 \\
\hline $\begin{array}{l}\text { Командная } \\
\text { работа }\end{array}$ & 0.141 & 0.059 & 0.132 & $0.624^{* *}$ & $0.251^{* *}$ & 0.020 \\
\hline Исследование & 0.066 & 0.045 & -0.006 & -0.054 & -0.044 & $0.313^{* *}$ \\
\hline Эскапизм & $0.522^{* *}$ & 0.129 & -0.135 & 0.074 & 0.122 & $0.188^{* *}$ \\
\hline $\begin{array}{l}\text { Отыгрывание } \\
\text { роли }\end{array}$ & $0.222^{* *}$ & 0.056 & -0.024 & -0.024 & 0.030 & $0.272^{* *}$ \\
\hline Кастомизация & 0.145 & 0.169 & -0.083 & 0.102 & 0.131 & 0.104 \\
\hline Достижение & $0.247^{* *}$ & $0.440^{* *}$ & $0.243^{* *}$ & $0.296^{* *}$ & $0.359^{* *}$ & 0.093 \\
\hline $\begin{array}{l}\text { Социальная } \\
\text { мотивация }\end{array}$ & $0.234^{* *}$ & 0.107 & 0.159 & $0.784^{* *}$ & $0.321^{* *}$ & 0.045 \\
\hline Погружение & $0.329^{* *}$ & 0.148 & -0.088 & 0.035 & 0.086 & $0.325^{* *}$ \\
\hline
\end{tabular}

$* * p<0.01$. 
также с фактором механики. Шкалы Ориентация на общение и Продуманность-Спонтанность - со всеми факторами Социальной мотивации и большинством факторов Достижения. Шкалы Активность-пассивность и Ориентация на достижение успеха демонстрируют значимые связи с механикой и прогрессом шкалы Достижение. Шкала Переживание опыта потока коррелирует с факторами из всех шкал опросника Йи, а именно с прогрессом (шкала Достижение), общением и отношениями (шкала Социальная мотивация), эскапизмом и отыгрыванием роли (шкала Погружение).

\section{Описательные статистики и оценка индивидуальных различий}

Описательные статистики по шкалам опросника мотивации игры в ММОРПГ были рассчитаны для выборки в целом и отдельно для мужчин и женщин. Межгрупповые сравнения выполнены с помощью t-критерия Стьюдента для независимых выборок. Результаты приведены в таблице 6.

Для мужчин характерны более высокие по сравнению с женщинами показатели механики и более низкие - эскапизма и кастомизации. Играя в ММОРПГ, мужчины больше интересуются лежащими в основе игры математическими формулами, пытаются разобраться, как работает игровой мир, в то

Сравнение средних показателей мужчин и женщин по шкалам опросника Ника Йи

Таблица 6

\begin{tabular}{|l|c|c|c|c|c|c|c|c|}
\hline \multirow{2}{*}{ Шкала } & \multicolumn{2}{|c|}{$\begin{array}{c}\text { Вся выборка } \\
\mathbf{( N = 5 3 8 )}\end{array}$} & \multicolumn{2}{c|}{$\begin{array}{c}\text { Женщины } \\
(\mathbf{n = 1 4 8}\end{array}$} & \multicolumn{2}{c|}{$\begin{array}{c}\text { Мужчины } \\
(\mathbf{n = 3 9 0 )}\end{array}$} & \multicolumn{2}{|c|}{$\begin{array}{c}\text { t-критерий } \\
\text { Стьюдента }\end{array}$} \\
\cline { 2 - 9 } & $\mathrm{M}$ & $\mathrm{SD}$ & $\mathrm{M}$ & $\mathrm{SD}$ & $\mathrm{M}$ & $\mathrm{SD}$ & $\mathrm{t}$ & $p$ \\
\hline Механика & 7.11 & 2.14 & 6.24 & 2.16 & 7.44 & 2.07 & -5.941 & 0.000 \\
\hline Прогресс & 6.25 & 2.36 & 6.54 & 2.43 & 6.15 & 2.33 & 1.735 & 0.083 \\
\hline Соревнование & 4.09 & 2.35 & 3.87 & 2.44 & 4.17 & 2.31 & -1.335 & 0.183 \\
\hline Общение & 6.78 & 2.57 & 7.00 & 2.71 & 6.69 & 2.51 & 1.251 & 0.212 \\
\hline Отношения & 8.03 & 3.35 & 8.40 & 3.74 & 7.89 & 3.18 & 1.458 & 0.146 \\
\hline Командная работа & 6.28 & 2.29 & 6.32 & 2.36 & 6.26 & 2.27 & 0.253 & 0.800 \\
\hline Исследование & 11.11 & 3.26 & 10.70 & 3.67 & 11.27 & 3.08 & -1.661 & 0.098 \\
\hline Эскапизм & 5.87 & 2.52 & 6.47 & 2.45 & 5.64 & 2.51 & 3.476 & 0.001 \\
\hline Отыгрывание роли & 9.25 & 3.09 & 9.59 & 3.11 & 9.12 & 3.07 & 1.571 & 0.117 \\
\hline Кастомизация & 9.98 & 3.47 & 11.34 & 3.20 & 9.47 & 3.44 & 5.767 & 0.000 \\
\hline Достижение & 17.45 & 4.63 & 16.66 & 4.77 & 17.76 & 4.54 & -2.475 & 0.014 \\
\hline Социальная мотивация & 21.08 & 7.07 & 21.72 & 7.74 & 20.84 & 6.80 & 1.206 & 0.229 \\
\hline Погружение & 40.36 & 8.99 & 42.43 & 8.88 & 39.57 & 8.93 & 3.311 & 0.001 \\
\hline
\end{tabular}


время как женщины более заинтересованы в создании персонажа с уникальной внешностью и стилем, а также более склонны использовать компьютерные игры для отвлечения от проблем в реальной жизни. По обобщенным шкалам значимые различия выявлены для шкал Достижение (выше у мужчин) и Погружение (выше у женщин), что также может указывать на специфику мотивационной привлекательности онлайновых игр для людей разного пола. Полученные результаты в целом согласуются с данными Н. Йи (Yеe, 2006), за исключением не выявленных в нашей работе различий по шкалам Социальной мотивации. Эти различия можно объяснить меньшим размером нашей выборки, а также изменениями, произошедшими в среде компьютерных игроков за последние 10-15 лет. В частности, среди геймеров становится больше женщин, и подобное увлечение перестает восприниматься как нечто необычное.

\section{Обсуждение результатов}

Факторная структура оригинального опросника Ника Йи воспроизводится на российской выборке. Показатели пригодности измерительной модели $(\mathrm{CFI}=0.95, \mathrm{RMSEA}=0.042)$ и оценки внутренней согласованности пунктов шкал русскоязычной версии опросника мотивации игроков в ММОРПГ, состоящей из 24 пунктов, позволяют рассматривать его как надежный психометрический инструмент.

Анализ корреляционных связей шкал опросника Йи и опросника GAMS показывает, что разные факторы игровой мотивации соотносятся как с внутренней, так и с различными аспектами внешней мотивации. Наиболее широко эти связи представлены для фактора прогресса шкалы Достижение и большинства факторов шкалы Погружение, за исключением мотивации исследования.

Корреляции прогресса с внутренней мотивацией, внешней и идентифицированной регуляцией показывают, что желание развивать своего игрового персонажа может проявляться в поиске вызова в игре и раскрытии своих игровых возможностей (внутренняя мотивация), а также в поиске сторонней награды (внешняя регуляция) и восприятии компьютерной игры как значимой деятельности, согласующейся с личными целями игрока (идентифицированная регуляция). Фактор механики, относящийся к шкале Достижение, связан только с внешней и интегративной регуляцией. Таким образом, интерес к технической стороне игрового процесса, математическим формулам, лежащим за ним, по-видимому, является внешним к мотивации игры и обуславливается стремлением к получению более высоких результатов, либо игра сама по себе выступает как способ достижения цели, например, при наличии интереса к программированию или гейм-дизайну (Иванова и др., 2016).

Все факторы Социальной мотивации значимо коррелируют с идентифицированной регуляцией. Это означает, что социальную мотивацию геймеров также следует рассматривать как внешнюю относительно игровой деятельности, что представляется логичным. В данном случае личными целями игрока, вероятно, являются социализация и выстраивание отношений с другими игроками, как внутри, так и за пределами игрового мира. Фактор отношений 
при этом связан и с внешней регуляцией. Это можно интерпретировать как восприятие внутриигровых отношений игроками в качестве фактора достижения успеха в ММОРПГ.

Все факторы Погружения значимо связаны со шкалой интегративной регуляции GAMS, а для фактора исследования эта корреляция единственно значимая. Интегративная регуляция в мотивации игровой деятельности подразумевает соотнесенность игры с образом жизни или внешними целями игрока (Там же), что, в частности, может отражать своеобразие мотивации, присущее игрокамисследователям, играющим не столько ради самой игры, сколько ради удовлетворения познавательной потребности. Другие факторы Погружения демонстрируют схожие корреляции с GAMS (за исключением эскапизма, связь которого с внешней регуляцией незначима). Эскапизм, отыгрывание роли и кастомизация коррелируют с внутренней мотивацией игры, интегративной регуляцией, а также интроецированной регуляцией. Последняя подразумевает обращение к игре под давлением чувства вины или тревоги. С одной стороны, эти формы мотивации могут свидетельствовать об использовании компьютерной игры как формы совладающего поведения с проблемами в реальности, но также указанные переживания могут проистекать из неспособности отказаться от игры, указывать на связь с компьютерной игровой зависимостью. В оригинальной публикации Йи также рассматривает эскапизм как фактор риска зависимости (Yeе, 2006).

Корреляции со шкалами опросника опыта потока также содержательно хорошо интерпретируются. Шкала переживания опыта потока демонстрирует значимые корреляции со всеми укрупненными шкалами опросника Ника Йи и большинством факторов, их составляющих. Опыт потока, вероятно, вносит свой вклад во все аспекты мотивации компьютерной игры, и, в свою очередь, разные аспекты игровой мотивации способствуют достижению переживания потока. Наибольшее количество корреляций с опытом потока продемонстрировали факторы механики и достижения, что, вероятно, адресует к такому условию возникновения опыта потока, как оптимальное соотношение требований задачи и навыков игрока (Войскунский и др., 2005). Ожидаемо факторы Социальной мотивации (а также фактор соревнования, наиболее «социальный» из шкалы Достижения) связаны с ориентацией на общение в игре. Продуманный стиль игры, проявляющийся как более осторожное, вдумчивое поведение с опорой на мнение опытных игроков, положительно связан со всеми факторами социальной мотивации, что указывает на взаимодействие данного стиля игры со сферой социальных взаимоотношений между игроками. Мотивация исследования значимо коррелирует с познавательной мотивацией, а эскапизм и отыгрывание роли - с переживанием потока, что отсылает нас к дискуссии о возможной роли опыта потока в формировании игровой зависимости (Andrade, Pontes, 2017). Познавательный же аспект отыгрывания роли, вероятно, имеет отношение к получению нового опыта и знаний через идентификацию себя с персонажем, погружение в драматургию сюжета, историю и особенности игрового мира. Таким образом, корреляционные связи с опросником опыта потока также подтверждают конструктную валидность опросника мотивации игры в ММОРПГ Ника Йи. 


\section{Выводы}

Русскоязычная версия опросника мотивации игроков в ММОРПГ Ника Йи воспроизводит факторную структур оригинального опросника и демонстрирует приемлемые показатели надежности по всем факторам. Корреляции со шкалами других опросников позволяют сделать вывод о высокой конструктной валидности адаптированного опросника. Данный опросник может использоваться при изучении мотивации онлайн-игроков.

\section{Ограничения}

Хорошие показатели пригодности измерительной модели были достигнуты путем частичного исключения вопросов из большинства шкал. Это может быть связано с особенностью выборки - не все участники исследования считали ММОРПГ любимым и основным для себя жанром, в то время как оригинальная версия опросника разрабатывалась с привлечением игроков исключительно в ММОРПГ, более популярные в 2000-е, нежели сейчас. Увеличение размера выборки, строгий учет жанровых предпочтений и опыта игры, а также использование эксплораторных процедур для выявления факторной структуры опросника позволят сделать более обоснованные выводы о его психометрических свойствах в будущем.

\section{Литература}

Ван, Ш., Войскунский, А. Е., Митина, О. В., Карпухина, А. И. (2011). Связь опыта потока с психологической зависимостью от компьютерных игр. Психология. Журнал Высшей школь экономики, 8(4), 73-101.

Войскунский, А. Е., Митина, О. В., Аветисова, А. А. (2005). Общение и «опыт потока» в групповых ролевых интернет играх. Психологический журнал, 26(5), 47-63.

Иванова Н. А. (2020). Мотивы вовлеченности мужчин в массовые онлайн-игры [Кандидатская диссертация, Санкт-Петербургский государственный университет]. URL: http://disser.spbu.ru/files/2020/disser_ivanova.pdf

Иванова, Н. А., Артемов, А. В., Волохонский, В. Л., Дубик, С. В. (2016). Мотивация онлайн-гейминга в контексте теории самодетерминации (SDT). Вестник Санкт-Петербургского университета. Психология, 2, 47-58. https://doi.org/10.21638/11701/spbu16.2016.206

Седых, И. А. (2020). Индустрия компьютерных игр-2020. https://dcenter.hse.ru/data/ 2020/07/27/1599127653/\%D0\%98\%D0\%BD\%D0\%B4\%D1\%83\%D1\%81\%D1\%82\%D1\%80\%D 0\%B8\%D1\%8F\%20\%D0\%BA\%D0\%BE\%D0\%BC\%D0\%BF\%D1\%8C\%D1\%8E\%D1\%82\%D0\% B5\%D1\%80\%D0\%BD\%D1\%8B\%D1\%85\%20\%D0\%B8\%D0\%B3\%D1\%80-2020.pdf

Фомичева, Ю. В., Шмелев, А. Г., Бурмистров, И. В. (1991). Психологические корреляты увлеченности компьютерными играми. Вестник Московского университета. Серия 14. Психология, 3, 27-39.

Ссылки на зарубежные источники см. в разделе References после англоязычного блока. 
Богачева Наталия Вадимовна - доцент, кафедра педагогики и медицинской психологии, Первый Московский государственный медицинский университет имени И.М. Сеченова (Сеченовский Университет), кандидат психологических наук.

Сфера научных интересов: киберпсихология, психология геймеров, компьютерная игровая зависимость.

Контакты: bogacheva.nataly@gmail.com

Епишин Виталий Евгеньевич - старший преподаватель, кафедра педагогики и медицинской психологии, Первый Московский государственный медицинский университет имени И.М. Сеченова (Сеченовский Университет).

Сфера научных интересов: психология риска и принятия решений, решение комплексных проблем, психометрика.

Контакты: v.e.epishin@gmail.com

Мильянская Алиса Валерьевна - психолог (частная практика), независимый исследователь. Сфера научных интересов: мотивационная сфера, виртуальное пространство, методы психодиагностики.

Контакты: milianskaya.alisa@gmail.com

Приложение

\section{Русскоязычная версия опросника мотивации игры в массовые многопользовательские ролевые онлайн-игры (ММОРПГ) Ника Йи}

Пожалуйста, ответьте на несколько вопросов, касающихся ваших интересов и предпочтений в онлайн-компьютерных играх, отметив наиболее подходящий для вас вариант в таблице. Здесь нет правильных и неправильных ответов.

\begin{tabular}{|c|c|c|c|c|c|c|}
\hline № & Вопрос & 1 & 2 & 3 & 4 & 5 \\
\hline 1. & $\begin{array}{l}\text { Насколько вам интересны точные цифры и } \\
\text { проценты, лежащие в основе игровой меха- } \\
\text { ники? }\end{array}$ & $\begin{array}{c}1 \\
\text { Совсем нет }\end{array}$ & 2 & 3 & 4 & $\begin{array}{c}5 \\
\text { Очень сильно }\end{array}$ \\
\hline 2. & $\begin{array}{l}\text { Вы предпочитаете состоять в группе или } \\
\text { быть соло (один)? }\end{array}$ & $\begin{array}{c}1 \\
\text { Однозначно } \\
\text { один }\end{array}$ & 2 & 3 & 4 & $\begin{array}{c}5 \\
\text { Однозначно } \\
\text { в группе }\end{array}$ \\
\hline 3. & $\begin{array}{l}\text { Насколько вам нравится работать с други- } \\
\text { ми игроками в команде? }\end{array}$ & $\begin{array}{c}1 \\
\text { Совсем нет }\end{array}$ & 2 & 3 & 4 & $\begin{array}{c}5 \\
\text { Очень сильно }\end{array}$ \\
\hline 4. & $\begin{array}{l}\text { Как много времени вы тратите, настраивая } \\
\text { вашего персонажа при его создании? }\end{array}$ & $\begin{array}{c}1 \\
\text { Совсем нет }\end{array}$ & 2 & 3 & 4 & $\begin{array}{c}5 \\
\text { Очень сильно }\end{array}$ \\
\hline 5. & $\begin{array}{l}\text { Насколько для вас важно, чтобы доспе- } \\
\text { хи/наряд вашего персонажа сочетались по } \\
\text { цвету и стилю? }\end{array}$ & $\begin{array}{c}1 \\
\text { Совсем нет }\end{array}$ & 2 & 3 & 4 & $\begin{array}{c}5 \\
\text { Очень сильно }\end{array}$ \\
\hline 6. & $\begin{array}{l}\text { Насколько для вас важно, чтобы ваш пер- } \\
\text { сонаж внешне отличался от других? }\end{array}$ & $\begin{array}{c}1 \\
\text { Совсем нет }\end{array}$ & 2 & 3 & 4 & $\begin{array}{c}5 \\
\text { Очень сильно }\end{array}$ \\
\hline 7. & $\begin{array}{l}\text { Насколько вам нравится исследовать игро- } \\
\text { вой мир только ради самого его исследова- } \\
\text { ния? }\end{array}$ & $\begin{array}{c}1 \\
\text { Совсем нет }\end{array}$ & 2 & 3 & 4 & $\begin{array}{c}5 \\
\text { Очень сильно }\end{array}$ \\
\hline 8. & $\begin{array}{l}\text { Насколько для вас важно находить квесты, } \\
\text { NPC (неигровых персонажей) или локации, } \\
\text { о которых большинство игроков не знает? }\end{array}$ & $\begin{array}{c}1 \\
\text { Совсем нет }\end{array}$ & 2 & 3 & 4 & $\begin{array}{c}5 \\
\text { Очень сильно }\end{array}$ \\
\hline 9. & $\begin{array}{l}\text { Насколько для вас важно в игре прокачи- } \\
\text { вать персонажа настолько быстро, } \\
\text { насколько это возможно? }\end{array}$ & $\begin{array}{c}1 \\
\text { Совсем нет }\end{array}$ & 2 & 3 & 4 & $\begin{array}{c}5 \\
\text { Очень сильно }\end{array}$ \\
\hline
\end{tabular}




\begin{tabular}{|c|c|c|c|c|c|c|}
\hline 10. & $\begin{array}{l}\text { Насколько для вас важно стать могуще- } \\
\text { ственным в игре? }\end{array}$ & $\begin{array}{c}1 \\
\text { Совсем нет }\end{array}$ & 2 & 3 & 4 & $\begin{array}{c}5 \\
\text { Очень сильно }\end{array}$ \\
\hline 11. & $\begin{array}{l}\text { Насколько для вас важно знать как можно } \\
\text { больше о механике и правилах игры? }\end{array}$ & $\begin{array}{c}1 \\
\text { Совсем нет }\end{array}$ & 2 & 3 & 4 & $\begin{array}{c}5 \\
\text { Очень сильно }\end{array}$ \\
\hline 12. & $\begin{array}{l}\text { Насколько для вас важно погружаться в } \\
\text { фантастический мир игры? }\end{array}$ & $\begin{array}{c}1 \\
\text { Совсем нет }\end{array}$ & 2 & 3 & 4 & $\begin{array}{c}5 \\
\text { Очень сильно }\end{array}$ \\
\hline 13. & $\begin{array}{l}\text { Насколько для вас важно уйти из реально- } \\
\text { го мира в игровой? }\end{array}$ & $\begin{array}{c}1 \\
\text { Совсем нет }\end{array}$ & 2 & 3 & 4 & $\begin{array}{c}5 \\
\text { Очень сильно }\end{array}$ \\
\hline 14. & $\begin{array}{l}\text { Насколько вам нравится в игре знакомить- } \\
\text { ся с другими игроками? }\end{array}$ & $\begin{array}{c}1 \\
\text { Совсем нет }\end{array}$ & 2 & 3 & 4 & $\begin{array}{c}5 \\
\text { Очень сильно } \\
\end{array}$ \\
\hline 15. & $\begin{array}{l}\text { Насколько вам нравится в игре болтать с } \\
\text { другими игроками? }\end{array}$ & $\begin{array}{c}1 \\
\text { Совсем нет }\end{array}$ & 2 & 3 & 4 & $\begin{array}{c}5 \\
\text { Очень сильно } \\
\end{array}$ \\
\hline 16. & $\begin{array}{l}\text { Насколько вам нравится исследовать каж- } \\
\text { дую локацию в игровом мире? }\end{array}$ & $\begin{array}{c}1 \\
\text { Совсем нет }\end{array}$ & 2 & 3 & 4 & $\begin{array}{c}5 \\
\text { Очень сильно } \\
\end{array}$ \\
\hline 17. & $\begin{array}{l}\text { Насколько вам нравится в игре делать } \\
\text { вещи, раздражающие других игроков? }\end{array}$ & $\begin{array}{c}1 \\
\text { Совсем нет }\end{array}$ & 2 & 3 & 4 & $\begin{array}{c}5 \\
\text { Очень сильно }\end{array}$ \\
\hline 18. & $\begin{array}{l}\text { Как часто в игре вы ведете содержатель- } \\
\text { ные беседы с другими игроками? }\end{array}$ & $\begin{array}{c}1 \\
\text { Никогда }\end{array}$ & 2 & 3 & 4 & $\begin{array}{c}5 \\
\text { Всегда } \\
\end{array}$ \\
\hline 19. & $\begin{array}{l}\text { Как часто в игре вы говорите о личном с } \\
\text { игровыми друзьями? }\end{array}$ & $\begin{array}{c}1 \\
\text { Никогда }\end{array}$ & 2 & 3 & 4 & $\begin{array}{c}5 \\
\text { Всегда }\end{array}$ \\
\hline 20. & $\begin{array}{l}\text { Как часто в игре ваши игровые друзья } \\
\text { предлагают вам помощь, когда у вас возни- } \\
\text { кают проблемы в реальной жизни? }\end{array}$ & $\begin{array}{c}1 \\
\text { Никогда }\end{array}$ & 2 & 3 & 4 & $\begin{array}{c}5 \\
\text { Всегда }\end{array}$ \\
\hline 21. & $\begin{array}{l}\text { Как часто в игре вы придумываете своим } \\
\text { персонажам прошлое и истории? }\end{array}$ & $\begin{array}{c}1 \\
\text { Никогда }\end{array}$ & 2 & 3 & 4 & $\begin{array}{c}5 \\
\text { Всегда }\end{array}$ \\
\hline 22 & $\begin{array}{l}\text { Как часто в игре вы отыгрываете роль } \\
\text { вашего персонажа (злобный глупый орк, } \\
\text { мудрый маг и т.д.)? }\end{array}$ & $\begin{array}{c}1 \\
\text { Никогда }\end{array}$ & 2 & 3 & 4 & $\begin{array}{c}5 \\
\text { Всегда }\end{array}$ \\
\hline 23. & $\begin{array}{l}\text { Как часто вы играете, чтобы не думать о } \\
\text { проблемах и заботах в реальной жизни? }\end{array}$ & $\begin{array}{c}1 \\
\text { Никогда }\end{array}$ & 2 & 3 & 4 & $\begin{array}{c}5 \\
\text { Всегда }\end{array}$ \\
\hline 24. & $\begin{array}{l}\text { Как часто в игре вы специально пытаетесь } \\
\text { спровоцировать или вывести из себя дру- } \\
\text { гих игроков? }\end{array}$ & $\begin{array}{c}1 \\
\text { Никогда }\end{array}$ & 2 & 3 & 4 & $\begin{array}{c}5 \\
\text { Всегда }\end{array}$ \\
\hline
\end{tabular}

\section{Ключи к опроснику (все пункты прямые)}

\begin{tabular}{|l|l|}
\hline \multicolumn{1}{|c|}{ Факторы } & \multicolumn{1}{c|}{ Номера вопросов } \\
\hline Механика & 1,11 \\
\hline Прогресс & 9,10 \\
\hline Соревнование & 17,24 \\
\hline Общение & 14,15 \\
\hline Отношения & $18,19,20$ \\
\hline Командная работа & 2,3 \\
\hline Исследование & $7,8,16$ \\
\hline Эскапизм & 13,23 \\
\hline Отыгрывание роли & $12,21,22$ \\
\hline Кастомизация & $4,5,6$ \\
\hline \multicolumn{1}{|c|}{ Шкалы } & \\
\hline Достижение & Механика + Прогресс + Соревнование \\
\hline Социальная мотивация & Общение + Отношения + Командная работа \\
\hline Погружение & Исследование + Эскапизм + Отыгрывание роли + Кастомизация \\
\hline
\end{tabular}




\title{
Adaptation of the Russian Version of Nick Yee's Motivations of Play in Massively Multiplayer Online Role-playing Games (MMORPGs) Inventory
}

\author{
N.V. Bogacheva ${ }^{\mathrm{a}}$, V.E. Epishin ${ }^{\mathrm{a}}$, A.V. Milianskaya \\ ${ }^{a}$ I.M. Sechenov First Moscow State Medical University (Sechenov University), 2 building 4 Bolshaya \\ Pirogozskaya Str., Moscow, 119991, Russian Federation
}

\begin{abstract}
The study aimed to adapt Nick Yee's Motivations of Play in MMORPGs Inventory into Russian. The sample included 538 participants (72.5\% male) aged $12-40$ years. We used Gaming Motivation Scale (GAMS) and the flow experience in group role-playing games questionnaire to assess the external validity of the adapted inventory scales. The final version of the questionnaire reproduced the original factor structure, but contained 24 items out of 39 . The indicators of the final model fit $(\mathrm{CFI}=0.95$; RMSEA $=0.042)$ demonstrated good agreement between the model and the empirical data. Cronbach`s alphas varied between $0.619-0.906$, suggesting moderate to good reliability. The correlations between Yee`s Inventory scales, GAMS scales, and the flow experience questionnaire confirmed its construct validity. Intrinsic motivation, integrated and introjected regulation (GAMS) mostly correlated with the factors of the Immersion scale. Identified and external regulation mainly correlated with social and achievement motivation factors. There were no significant correlations for GAMS amotivation scale. All scales of Yee`s Inventory correlated with the flow experience; multiple correlations were also found between achievement and social motivation factors and focus on communication and thoughtfulnessspontaneity factors of the flow experience questionnaire. Male and female gamers scored differently in Yee's Inventory: men had a significantly higher interest in mechanics (achievement scale). Women had higher escapism and customization motivations (immersion scale). We consider the adapted version of Yee's Inventory a reliable and valid tool to evaluate online gaming motivation.
\end{abstract}

Keywords: computer games, video games, gaming motivation, gamers, online games, questionnaire adaptation.

\section{References}

Andrade, M. J., \& Pontes, H. M. (2017). A brief update on videogame play and flow experience: From addiction to healthy gaming. Mental Health and Addiction Research Journal, 2(1), 1-3. https://doi.org/10.15761/MHAR.1000127

Bartle, R. (1996). Hearts, clubs, diamonds, spades: Players who suit MUDs. The Journal of Virtual Environments, 1. https://mud.co.uk/richard/hcds.htm

Fomicheva, Y. V., Shmelev, A. G., \& Burmistrov, I. V. (1991) Psikhologicheskie korrelyaty uvlechennosti komp'juternymi igrami [Psychological correlates of computer games enthusiasm]. Moscow University Psychology Bulletin, 3, 27-39. 
Hu, L., \& Bentler, P. M. (1999). Cutoff criteria for fit indexes in covariance structure analysis: Conventional criteria versus new alternatives. Structural Equation Modeling: A Multidisciplinary Journal, 6(1), 1-55. https://doi.org/10.1080/10705519909540118

Ivanova, N. A. (2020). Motivy vovlechennosti muzhchin v massovye onlajn-igry [Motives of male engagement in massive online games] [PhD Thesis, Saint Petersburg State University].

Ivanova, N. A., Artemov, A. V., Volokhovskiy, V. L., \& Dubik, S. V. (2016). Online gaming motivation according to self-determination theory (SDT). Vestnik of Saint Petersburg University. Psychology, 2, 47-58. https://doi.org/10.21638/11701/spbu16.2016.206 (in Russian)

Lafrenière, M.-A. K., Verner-Filion, J., \& Vallerand, R. J. (2012). Development and validation of the Gaming Motivation Scale (GAMS). Personality and Individual Differences, 53(7), 827-831. https://doi.org/10.1016/j.paid.2012.06.013

Olson, C. K. (2010). Children's motivations for video game play in the context of normal development. Review of General Psychology, 14(2), 180-187. https://doi.org/10.1037/a0018984

Ryan, R. M., Rigby, C. S., \& Przybylski, A. (2006). The motivational pull of video games: A self-determination theory approach. Motivation and Emotion, 30(4), 347-363. https://doi.org/10.1007/s11031-006-9051-8

Sedyh, I. A. (2020). Industrija kompjuternyh igr-2020 [Computer Games Industry-2020]. https://dcenter.hse.ru/data/2020/07/27/1599127653/\%D0\%98\%D0\%BD\%D0\%B4\%D1\%83\% D1\%81\%D1\%82\%D1\%80\%D0\%B8\%D1\%8F\%20\%D0\%BA\%D0\%BE\%D0\%BC\%D0\%BF\%D1\% 8C\%D1\%8E\%D1\%82\%D0\%B5\%D1\%80\%D0\%BD\%D1\%8B\%D1\%85\%20\%D0\%B8\%D0\%B3\% D1\%80-2020.pdf

Sellers, M. (2006). Designing the experience of interactive play. In P. Vorderer \& J. Bryant (Eds.), Playing video games. Motives, responses and consequences (1st ed., pp. 9-22). Routledge.

Voiskounsky, A. E., Mitina, O. V., \& Avetisova, A. A. (2005). Communication and "flow experience" in Internet group role games. Psikhologicheskii Zhurnal, 26(5), 47-63. (in Russian)

Wang, Sh., Voiskounsky, A. E., Mitina, O. V., \& Karpukhina, A. I. (2011). Association of flow experience to psychological computer game dependency. Psychology. Journal of Higher School of Economics, 8(4), 73-101. (in Russian)

Yee, N. (2006). Motivations for play in online games. CyberPsychology \& Behavior, 9(6), 772-775. https://doi.org/10.1089/cpb.2006.9.772

Nataliya V. Bogacheva - Associate Professor, Department of Pedagogy and Medical Psychology, I.M. Sechenov First Moscow State Medical University (Sechenov University), PhD in Psychology.

Research Area: cyberpsychology, psychology of gamers, gaming addiction.

E-mail: bogacheva.nataly@gmail.com

Vitalii E. Epishin - Senior Lecturer, Department of Pedagogy and Medical Psychology, I.M. Sechenov First Moscow State Medical University (Sechenov University).

Research Area: psychology of risk and decision making, solving complex problems, psychometrics.

E-mail: v.e.epishin@gmail.com

Alisa V. Milianskaya - Psychologist in private practice, independent researcher.

Research Area: motivational personality sphere, virtual space, psychodiagnostic methods.

E-mail: milianskaya.alisa@gmail.com 